\title{
Rethinking Procrastination: Positive Effects of "Active" Procrastination Behavior on Attitudes and Performance
}

\author{
ANGELA HSIN CHUN CHU \\ Department of Organizational Psychology \\ Columbia University \\ New York, New York \\ JIN NAM CHOI \\ Faculty of Management \\ McGill University \\ Montreal, Quebec, Canada
}

\begin{abstract}
Researchers and practitioners have long regarded procrastination as a selfhandicapping and dysfunctional behavior. In the present study, the authors proposed that not all procrastination behaviors either are harmful or lead to negative consequences. Specifically, the authors differentiated two types of procrastinators: passive procrastinators versus active procrastinators. Passive procrastinators are procrastinators in the traditional sense. They are paralyzed by their indecision to act and fail to complete tasks on time. In contrast, active procrastinators are a "positive" type of procrastinator. They prefer to work under pressure, and they make deliberate decisions to procrastinate. The present results showed that although active procrastinators procrastinate to the same degree as passive procrastinators, they are more similar to nonprocrastinators than to passive procrastinators in terms of purposive use of time, control of time, self-efficacy belief, coping styles, and outcomes including academic performance. The present findings offer a more sophisticated understanding of procrastination behavior and indicate a need to reevaluate its implications for outcomes of individuals.
\end{abstract}

Key words: coping strategies, procrastination, self-efficacy, time management

INVESTIGATORS HAVE DEFINED PROCRASTINATION as the lack or absence of self-regulated performance and the behavioral tendency to postpone what is necessary to reach a goal (Ellis \& Knaus, 1977; Knaus, 2000). The growing body of literature has demonstrated that procrastination is not just a problem of time management. It is a complex process that involves affective, cognitive, and behavioral components (Fee \& Tangney, 2000). Blunt and Pychyl (1998) and 
Harriott and Ferrari (1996) have found procrastination to be a prevalent phenomenon in the general population, chronically affecting a substantial portion of adults as well as university students. Procrastination may have particularly serious consequences for university students, whose lives are characterized by frequent deadlines. For example, Tice and Baumeister (1997) reported that university students who rated high on procrastination not only received low grades but also reported a high level of stress along with poor self-rated health.

Most of the existing literature on procrastination has contrasted procrastinators with nonprocrastinators. Procrastination has been considered a selfhandicapping behavior that leads to wasted time, poor performance, and increased stress. Investigators such as Ferrari (2001) have often depicted procrastinators as lazy or self-indulgent individuals who are unable to self-regulate. In contrast, nonprocrastination has been associated with high efficiency, productivity, and superior performance, and nonprocrastinators are often described as organized and highly motivated individuals (e.g., Bond \& Feather, 1988; Ellis \& Knaus, 1977).

Although both the practical literature and the academic literature have associated negative connotations to procrastination, investigators have found that procrastination can induce some short-term benefits. For example, Tice and Baumeister (1997) reported that compared with nonprocrastinators, procrastinators experience less stress and have better physical health when deadlines are far off. In this sense, procrastination can be seen as a strategy that they use to regulate negative emotions, thereby making the individual feel better, at least temporarily (Baumeister, Heatherton, \& Tice, 1994). Moreover, in principle, whether a person does a task far ahead of a deadline or only slightly ahead of it does not necessarily affect the quality of the work (Tice \& Baumeister). Therefore, practically speaking, procrastination does not necessarily have a negative impact on the effectiveness of the task performance.

In a similar vein, Knaus (2000) argued that not all delays lead to negative outcomes. For example, delays resulting from time that was spent planning and gathering vital preparatory information can be beneficial (Knaus). Many people claim that even when they start to work at the last minute, they can still finish on time and that they tend to work better and faster or generate more creative ideas under time pressure. This line of thought on procrastination suggests that there might be more than one kind of procrastinator and that in some cases procrastination behavior might lead to positive outcomes. In the present study, we identify two types of procrastinators and examine whether they have distinct characteristics in terms of the use and perception of time, their self-efficacy beliefs, their motivational orientation, their stress-coping strategies, and their personal outcomes.

Address correspondence to Jin Nam Choi, McGill University, Faculty of Management, 1001 Sherbrooke Street West, Montreal, Quebec, Canada H3A 1G5; jinnam.choi@ mcgill.ca (e-mail). 


\section{Passive and Active Procrastination}

Addressing the possibility that not all procrastination behaviors have negative effects, we conceptually distinguished two different types of procrastinators: passive versus active procrastinators. Passive procrastinators are procrastinators in the traditional sense. Cognitively, passive procrastinators do not intend to procrastinate, but they often end up postponing tasks because of their inability to make decisions quickly and to thereby act on them quickly. Active procrastinators, in contrast, are capable of acting on their decisions in a timely manner. However, they suspend their actions deliberately and focus their attention on other important tasks at hand. Therefore, passive procrastinators differ from active procrastinators on cognitive, affective, and behavioral dimensions.

Affectively, when a deadline approaches, passive procrastinators feel pressured and become pessimistic in their outlook, especially about their ability to achieve satisfactory results (Ferrari, Parker, \& Ware, 1992). Their thoughts of self-doubt and inadequacy increase the chance of failure and induce feelings of guilt and depression (Steel, Brothen, \& Wambach, 2001). Active procrastinators, on the other hand, like to work under pressure. When faced with last-minute tasks, they feel challenged and motivated, and that feeling immunizes them against the kind of suffering common in passive procrastinators. Different cognitive pathways and affective responses interact to produce different behavioral patterns: Active procrastinators are persistent and able to complete tasks at the last minute. Passive procrastinators, on the other hand, are more likely to give up and fail to complete tasks.

On the basis of the above circumstances, we proposed that active procrastination is a multifaceted phenomenon that includes cognitive (decision to procrastinate), affective (preference for time pressure), and behavioral (task completion by the deadline) components as well as the physical results and satisfaction with them. Because of these fundamental differences (cognitive, affective, and behavioral), we expected active and passive procrastinators to have distinct psychological characteristics and to achieve different outcomes.

\section{Time Use and Perception}

One of the most common recommendations for effective management of time is to properly structure one's use of time in combination with a clear sense of purpose. For example, Dipboye and Phillips (1990) showed that university students who had more sense of purpose and structure in their use of time reported greater psychological well-being and more efficient habits of study. Also, Vodanovich and Seib (1997) illustrated that procrastinators tend to have weak, if any, structure in their time use. Therefore, we expected nonprocrastinators, who tend to plan their activities on a day-to-day basis, to have time use that is more 
structured and to perceive their use of time to be more purposive. Traditional (passive) procrastinators, who incorporate less structure in their time use, may drift aimlessly from one activity to another (Bond \& Feather, 1988). Active procrastinators, in contrast, are expected to be different from passive procrastinators in having more time structure and a better sense of purpose in their time use because they are able to make deliberate decisions regarding their time use on the basis of urgency or priority. In this sense, active procrastinators are similar to nonprocrastinators in terms of engagement in time-structuring behaviors and purposive use of time.

Despite the fact that we can measure time, our perception of time is a truly subjective experience (Macan, 1994). Lay (1990) found passive procrastinators to underestimate the overall time that was required to complete tasks. Consequently, they often failed to complete tasks on time, triggering the perception of reduced control of time (Lay \& Schouwenburg, 1993). In contrast, nonprocrastinators, who constantly engage in planning and organizing, tend to have more realistic perceptions of time and to perceive more control over their time (Macan). Active procrastinators may be similar to nonprocrastinators in that they take charge of their time and try to maximize the efficiency of their time use. Consequently, they would develop an awareness of their time use and a perception of time control.

Hypothesis 1: Both nonprocrastinators and active procrastinators will report more time structure, more purposive use of time, and greater perception of control of time than will passive procrastinators. Nonprocrastinators and active procrastinators are not different on these dimensions.

\section{Self-Efficacy}

The association between self-efficacy and procrastination was first introduced by Bandura (1986). Self-efficacy refers to the belief that one can reliably perform the tasks that are required for successful goal achievement (Bandura, 1977). Bandura (1986) hypothesized that when adequate levels of ability and motivation exist, selfefficacy belief will affect a person's task initiation and persistence. Several investigators have examined the relationship between self-efficacy and procrastination. For example, Ferrari et al. (1992) and Tuckman (1991) have found an inverse relationship between self-efficacy belief and academic procrastination among college students. In line with the belief that self-efficacy plays a role in task initiation and task persistence, in the present study we expected that nonprocrastinators will have a stronger self-efficacy belief than passive procrastinators. As with nonprocrastinators, we expected active procrastinators to have a stronger self-efficacy belief than do passive procrastinators. Active procrastinators postpone tasks and direct their attention toward more urgent issues because they feel that they have control over their time use (Hypothesis 1) and are confident in their ability to finish tasks on time. 
Hypothesis 2: Both nonprocrastinators and active procrastinators will report stronger self-efficacy beliefs than will passive procrastinators. Nonprocrastinators and active procrastinators are not different on this dimension.

\section{Motivational Orientation}

Motivation is a force that drives a person to engage in a particular activity. Investigators have identified two types of motivation: intrinsic and extrinsic. According to Deci and Ryan (1985), intrinsic motivation refers to motivation that results from an internal drive. Extrinsic motivation, in contrast, refers to motivation that results from either positive or negative external contingencies. Brownlow and Reasinger (2000) found that both intrinsic motivation and extrinsic motivation were negatively related to academic procrastination. Conti (2000) suggested that although extrinsic motivation was necessary to prevent task delay, participants with intrinsic motivation devoted more time to their projects than did participants with extrinsic motivation.

On the basis of these findings (Brownlow \& Reasinger, 2000; Conti, 2000), we hypothesized that nonprocrastinators are motivated by both extrinsic motivation and intrinsic motivation because nonprocrastinators tend to not delay task performance and to perhaps spend more time on the task. In contrast, because of their frequent task delay and task incompletion, passive procrastinators seem to have low intrinsic motivation and extrinsic motivation. Finally, we speculated that active procrastinators have relatively high levels of extrinsic motivation but low levels of intrinsic motivation. Active procrastinators are able to finish tasks at the last minute, but they do not devote more time than necessary to each task. Their orientation toward work and life may be to achieve as much as possible in the least possible time, manifesting a value that is more closely aligned with extrinsic motivation than with intrinsic motivation.

Hypothesis $3 a$ : Both nonprocrastinators and active procrastinators will report a higher level of extrinsic motivation than that which passive procrastinators will report. Nonprocrastinators and active procrastinators are not different on this dimension.

Hypothesis 3b: Nonprocrastinators will report a higher level of intrinsic motivation than those that active procrastinators and passive procrastinators will report.

\section{Stress-Coping Strategy}

When dealing with stress, individuals try to remove the threat from the stressor or to reduce the discomfort caused by the stressor (Latack \& Havlovic, 1992). The three most frequently mentioned coping strategies include task-oriented strategies, emotion-oriented strategies, and avoidance-oriented strategies (Carver, Scheier, \& Weintraub, 1989; Endler \& Parker, 1990, 1994; Kosic, 2004). Task-oriented coping strategies reduce stress by focusing on immediate problems. Emotion- 
oriented coping strategies involve diminishing the emotional distress that is induced by the stressors. And avoidance-oriented coping strategies involve ignoring a problem or distracting oneself from it. Although most stressors elicit a mixture of coping strategies, task-oriented strategies predominate when individuals feel that they can do something constructive in regard to the situation, and emotion- and avoidance-oriented strategies emerge when people feel that they do not have much control over the stressors (Folkman \& Lazarus, 1980). Therefore, a person's self-efficacy level partially determines which coping strategy he or she will use.

Expanding this line of thought, we expected that nonprocrastinators will use task-oriented coping strategies to alleviate stress by considering realistic alternatives in response to problems they face. Nonprocrastinators may have a higher level of self-efficacy belief (Hypothesis 2) and thus believe that they have some control over the stressors and are capable of improving their situation. As a result, instead of engaging in irrelevant tasks or self-handicapping behaviors, they will choose to work on solving the problems at hand. Similarly, active procrastinators will use task-oriented coping, because their high level of self-efficacy belief makes them feel competent to overcome stressful circumstances.

In contrast, we expected passive procrastinators to use either emotion- or avoidance-oriented coping strategies when encountering stressful events. Ferrari and Tice (2000) found that procrastinators were more concerned about their selfimage than were nonprocrastinators, offering another explanation for the coping strategy that was used. Low self-efficacy belief and concern for poor self-image together make passive procrastinators feel powerless and cause them to actively avoid negative situations. As a result, they may cry, complain, or whine to express their frustration and fears; they may engage in trivial, irrelevant tasks to distract themselves; or they may ignore tasks completely.

Hypothesis 4: In stressful situations, nonprocrastinators and active procrastinators will use task-oriented coping strategies, and passive procrastinators will use either emotion- or avoidance-oriented coping strategies.

\section{Personal Outcomes}

Investigators have reported that procrastination leads to low academic achievement, elevated levels of anxiety, stress, feelings of hopelessness, depression, and poor physical health; the opposite patterns have been observed among nonprocrastinators (Beswick, Rothblum, \& Mann, 1988; Bond \& Feather, 1988; Dipboye \& Phillips, 1990; Ellis \& Knaus, 1977; Owens \& Newbegin, 1997; Tice \& Baumeister, 1997). In the present study, we examined four outcome variables: stress, depression, life satisfaction, and performance level as indicated by grade point average (GPA). Because previous studies have revealed opposite outcome patterns between passive procrastination and nonprocrastination with the four outcome variables, we expected to obtain similar results in the present study. 
On the basis of our conceptualization of active procrastinators, we expected them to achieve positive outcomes rather than negative outcomes. As discussed earlier in the present article, active procrastinators are more likely to engage in behaviors of time management, perceive their use of time to be more purposive, and feel more control over their use of time than do passive procrastinators. Based on the existing findings of the positive association between patterns of time use or perception and individual well-being (Bond \& Feather, 1988; Macan, 1994; Macan, Shahani, Dipboye, \& Phillips, 1990), constructive time-related perception and behavior among active procrastinators will reduce their stress and depression, inducing increased life satisfaction and academic performance.

The positive outcomes of active procrastinators may also derive from their self-efficacy belief, motivation, and stress-coping strategies that we hypothesized in the preceding sections. Compared with passive procrastinators, active procrastinators have greater confidence in their own abilities in overcoming obstacles. As task-oriented individuals, active procrastinators direct their attention and actions toward pressing problems, offering themselves a greater chance of solving them in a satisfactory manner. Active procrastinators are extrinsically motivated and attempt to maximize their time utility, possibly leading to more successful task completion. Because successful task completion among nonprocrastinators reduces stress and feelings of depression and increases life satisfaction and academic performance (e.g., Dipboye \& Phillips, 1990; Tice \& Baumeister, 1997), in the present study we expected the same positive outcomes among active procrastinators.

Hypothesis 5: Both nonprocrastinators and active procrastinators will report a lower level of stress and depression, greater life satisfaction, and a higher GPA than passive procrastinators. Nonprocrastinators and active procrastinators are not different on these dimensions.

\section{Method}

\section{Participants and Procedure}

Participants were 230 undergraduate students (166 women [72.2\%], 64 men [27.8\%]) from three Canadian universities. The mean age of the sample was 21.49 years $(S D=2.23$ years). The distribution of participants' racial background was as follows: $53.7 \%$ Asian, 33.3\% White, 6.5\% Hispanic, 1.5\% African American, and 5.0\% other. Regarding first language, $47.8 \%$ of the participants reported English, 32\% reported Chinese, $7.9 \%$ reported French, and $12.3 \%$ reported other. The majority $(96.5 \%)$ of participants were full-time students, and the average year at university was 2.67 years. We invited participants to take part in the study by filling out a questionnaire entitled "Survey of University Students' Time Use." Participation was entirely voluntary, and participants completed the questionnaire at their own convenience. 


\section{Measures}

To measure the study variables, we used multi-item scales with acceptable internal consistencies. Whenever possible, we adopted existing measures with demonstrated validity and reliability. A 7-point Likert-type scale $(1=$ not at all true, 7 = very true) was used as the response format for all items.

Academic procrastination. To measure the degree of procrastination, we adopted six items $(\alpha=.82)$ from two existing measures of procrastination (L. Mann's [1982] Decisional Procrastinational Scale, as cited in Ferrari, Johnson, \& McCown, 1995; H. C. Schouwenburg's [1995] "Academic Procrastination: Theoretical Notions, Measurement, and Research," as cited in Ferrari et al.; e.g., "I tend to leave things until the last minute").

Active procrastination. Based on our conceptualization, we developed a 12-item scale $(\alpha=.67)$ to distinguish active procrastinators from passive procrastinators. The scale was designed to measure four defining characteristics of active procrastinators: (a) preference for pressure (e.g., "I tend to work better under pressure"), (b) intentional procrastination (e.g., "I intentionally put off work to maximize my motivation"), (c) ability to meet deadlines (e.g., "Since I often start working on things at the last moment, I have trouble finishing assigned tasks most of the time" [reverse coded]), and (d) outcome satisfaction (e.g., "I feel that putting work off until the last minute does not do me any good" [reverse coded]). We tested the factor structure of the 12 items measuring active procrastination using principal-component extraction with varimax rotation. This exploratory analysis generated four factors that confirm the hypothesized factor structure, with high factor loadings on the corresponding factors (all greater than .50) and low cross-loadings (all less than .24). (Complete results of factor analysis and items are available from Jin Nam Choi on request.) We used a composite measure of these four subscales to assess the overall level of the tendency of individuals toward active procrastination.

Patterns of time use. Adopting items from the Time Structure Questionnaire (Bond \& Feather, 1988), we assessed two aspects of time use. One was the structure of time use (3 items, $\alpha=.70$, e.g., "I have a daily routine, which I follow"), and the other was purposive use of time ( 3 items, $\alpha=.73$, e.g., "I often feel that my life is aimless, with no definite purpose").

Perception of time control. To measure participants' perceptions of control of their time, we used two items $(\alpha=$.66) developed by Macan et al. (1990; e.g., "I feel in control of my time" and "I can use my time the way I want to use it").

Self-efficacy belief. The self-efficacy belief scale included four items $(\alpha=.76)$ drawn from the Generalized Self-Efficacy Scale (Schwarzer \& Jerusalem, 
$1995)$ to measure individuals' beliefs about their ability to successfully perform desired tasks (e.g., "I believe that I can solve most problems if I invest enough effort").

Motivational orientation. The motivation scale contained seven items from Shia's (1998) Academic Motivation Questionnaire. We measured both extrinsic motivation (3 items, $\alpha=.70$, e.g., "Getting a good grade in my classes is the most satisfying thing for me right now") and intrinsic motivation (4 items, $\alpha=.75$, e.g., "I like courses that arouse my curiosity, even if they are difficult") for school activities.

Stress-coping strategy. To assess how participants respond to stressful situations, we adopted items from the Proactive Coping Inventory (Greenglass, Schwarzer, \& Taubert, 1999): (a) task-oriented coping behavior (3 items, $\alpha=.71$, e.g., "I just focus on the task to get what I want"), (b) emotion-oriented coping behavior (3 items, $\alpha=.82$, e.g., "I get out and talk to others to deal with stress"), and (c) avoidance-oriented coping behavior ( 3 items, $\alpha=.67$, e.g., "I try to turn my attention away from the problem").

Stress. We used a four-item scale $(\alpha=.77)$ to measure the level of stress that individuals had experienced in the previous month (MacArthur \& MacArthur, 2001; e.g., "In the past one month, how often did you feel difficulties were piling up so high that you could not overcome them?"). Each statement was rated on a 7-point Likert-type scale $(1=$ never, $7=$ very often $)$.

Depression. We used a four-item scale $(\alpha=.73)$ to measure the level of depression (Sheikh \& Yesavage, 1982; e.g., "I often feel downhearted and blue").

Life satisfaction. This scale consisted of four items $(\alpha=.82)$ that assess students' general satisfaction with life (e.g., "In general, I am satisfied with my life").

Academic performance. For a measure of academic performance, participants reported their GPA.

\section{Results}

Table 1 presents means, standard deviations, and correlation coefficients among the scales used in the present study. The correlation between the academic procrastination scale and the active procrastination scale was .03 ( $p>.60)$, indicating that these two scales were independent and that they measured nonoverlapping conceptual domains. Virtually all correlations involving academic procrastination and active procrastination were in the hypothesized directions. 


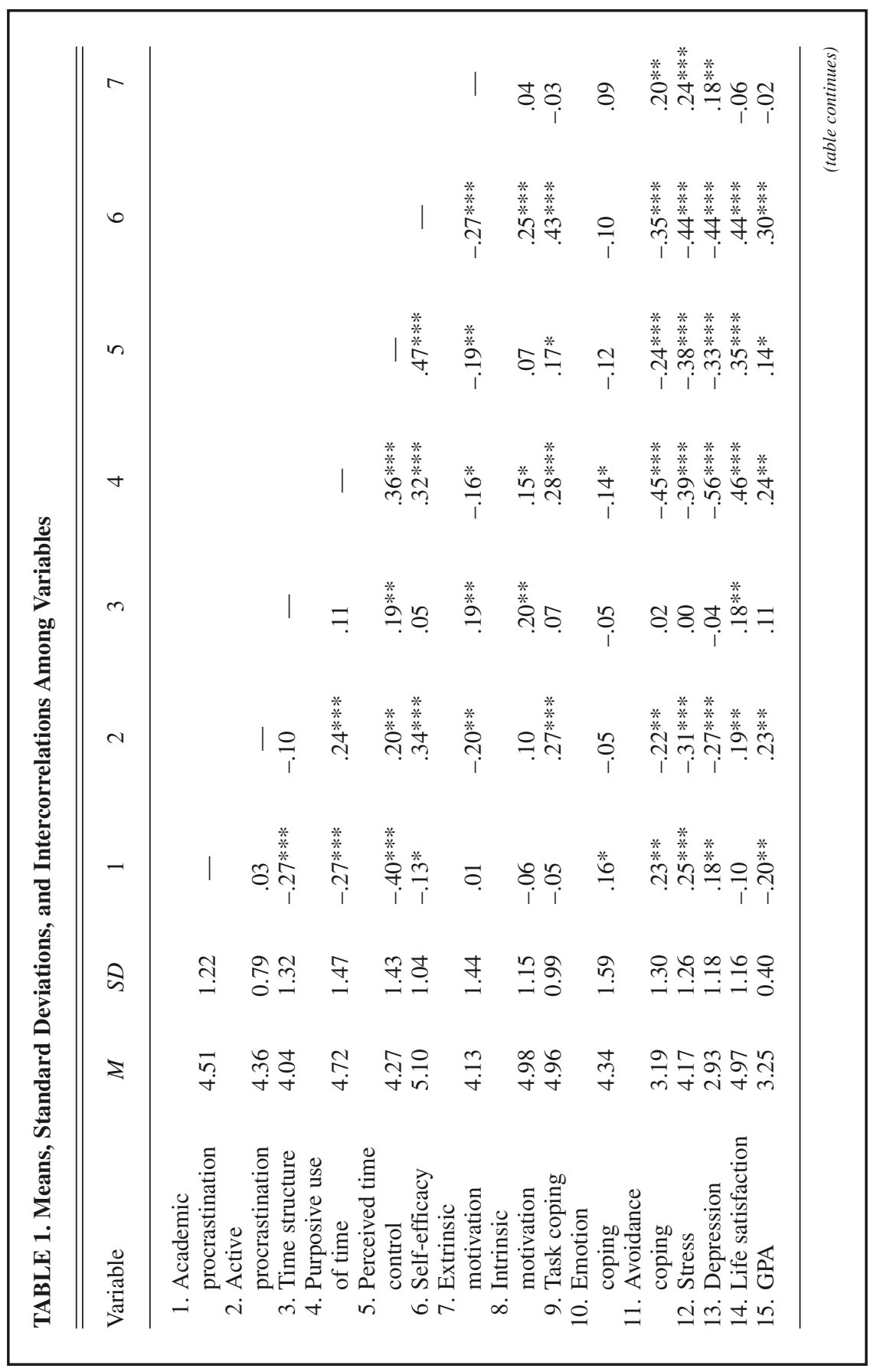




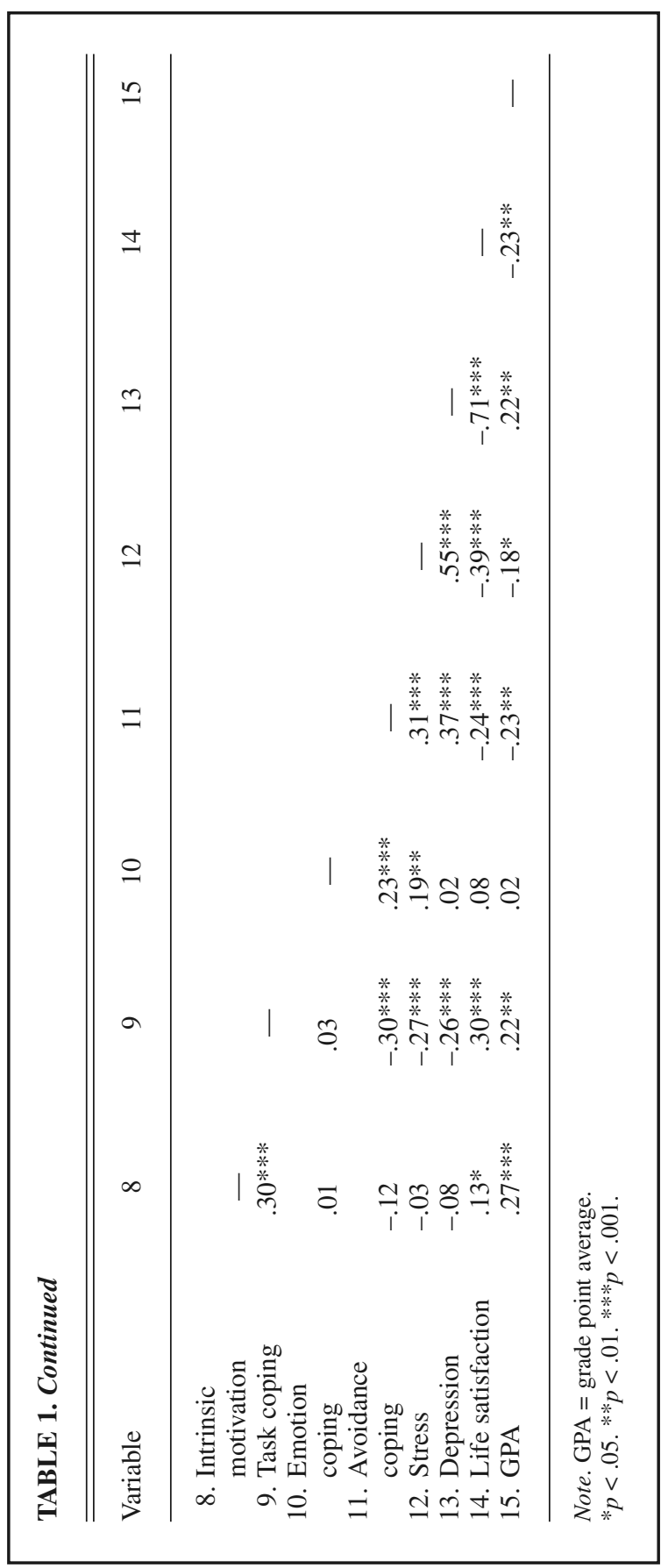




\section{Comparing the Three Groups Using One-Way Analysis of Variance (ANOVA)}

The present hypotheses involved a series of comparisons among three distinct groups of people: nonprocrastinators, passive procrastinators, and active procrastinators. To test the hypotheses, we created three equal-sized subgroups from the entire sample in a two-step process. First, nonprocrastinators were separated from procrastinators. We categorized participants who scored less than 4 (which was the midpoint of a 7-point scale) on the academic procrastination scale as nonprocrastinators and categorized those who scored greater than 4 as procrastinators. In our sample of 230 participants, 77 were categorized as nonprocrastinators, and 153 were categorized as procrastinators. Admittedly, using a scale midpoint to distinguish between procrastinators and nonprocrastinators might be somewhat arbitrary for the purpose of identifying procrastinators (cf. Brownlow \& Reasinger, 2000). However, we used this procedure intentionally here to compare nonprocrastinators with different types of procrastinators with increased statistical power, rather than comparing "chronic" procrastinators with "pathological" procrastinators.

In the second step, we further divided the 153 procrastinators into two groups: passive procrastinators and active procrastinators. To create two groups of comparable sizes, we chose 4.33 as the cutoff point on the active procrastination scale. Participants who scored less than 4.33 were categorized as passive procrastinators $(n=74)$, and participants who scored greater than 4.33 were categorized as active procrastinators $(n=79)$.

Table 2 presents the results of a one-way ANOVA, in which we compared the means of the study variables among the three groups. The first row in Table 2 shows the comparison of the level of procrastination across the three groups of individuals as identified earlier in the present article. Paired $t$ tests indicate that passive and active procrastinators reported significantly more academic procrastination than did nonprocrastinators $(p<.001)$, whereas they were not different from each other, mean difference $=.10, t(151)=.84$. Because we compared three groups, applying the Bonferroni procedure (Rosenthal \& Rosnow, 1991, pp. $329-332)$, we used an adjusted alpha level $(.5 \div 3=.017)$ as the criterion for statistical significance of $t$ tests. In addition, for each inferential test, effect estimates in Cohen's $d$ were provided (Rosenthal \& Rosnow, pp. 301-317).

Time use and perception. The results of the ANOVA shown in Table 2 indicated that, as we hypothesized, there were significant mean differences in patterns of time use and time perception among the three groups. Nonprocrastinators and active procrastinators showed higher levels of purposive use of time and time control than did passive procrastinators $(F=7.34, p<.01$, and $F=19.50, p<.001$, respectively; for all $F$ tests hereafter, $d f=2,227$, effect size estimates in Cohen's $d$ ranging between 0.41 and 1.06 , all significant at $p<.001)$. Nonprocrastinators reported greater perceived time control than did active procrastinators $(d=.56$, 


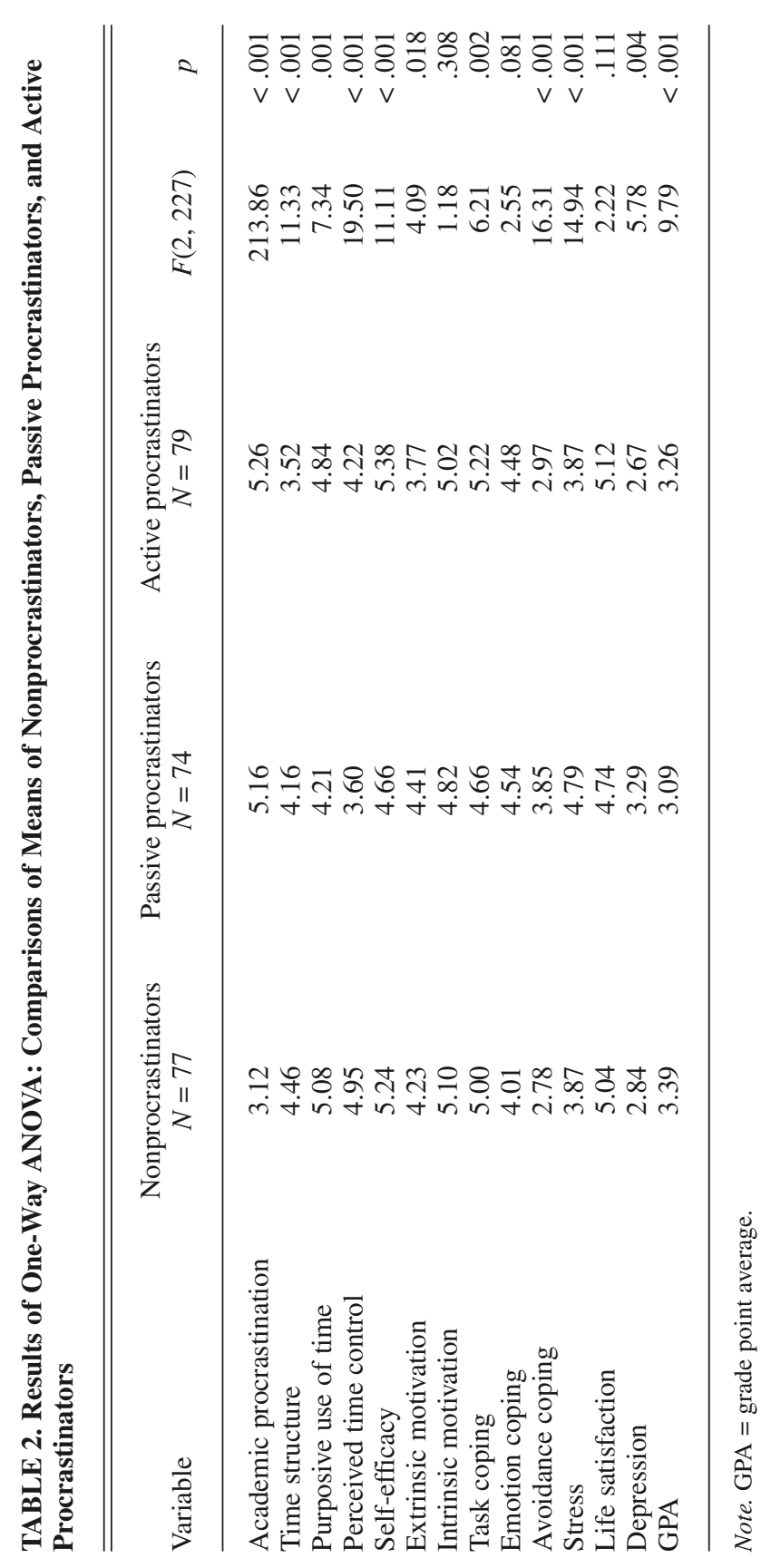


$p<.001$ ), but the difference between the two groups in purposive use of time was not significant $(d=.17, n s)$. Surprisingly, however, active procrastinators reported a lower level of time structure than did the other two groups (both $d \mathrm{~s}>.49, p$ $<.01)$, and the difference between nonprocrastinators and passive procrastinators was not significant $(d=.25, n s)$. We will address this counterintuitive pattern regarding time structure later in the present article.

Self-efficacy belief. Passive procrastinators had a significantly lower self-efficacy belief than did the other two groups (both $d \mathrm{~s}>.53, p<.001$ ). No meaningful difference was found between nonprocrastinators and active procrastinators $(d=$ $.15, n s)$. Therefore, Hypothesis 2 was supported.

Motivational orientation. In Hypotheses 3a and 3b, we suggested that nonprocrastinators and active procrastinators would display higher extrinsic motivation than would passive procrastinators and that nonprocrastinators would exhibit higher intrinsic motivation than would both types of procrastinators. A significant difference was found in extrinsic motivation $(F=4.09, p<.05)$ but not in intrinsic motivation. Interestingly, passive procrastinators exhibited a higher level of extrinsic motivation than did active procrastinators $(d=.43, p<.01)$. On the basis of the Bonferroni-adjusted criterion, the other two mean comparisons were not significant $(d<.33, p>.04)$. Therefore, Hypotheses $3 \mathrm{a}$ and $3 \mathrm{~b}$ were not supported.

Stress-coping strategy. Hypothesis 4 posited that when facing stressful situations, nonprocrastinators and active procrastinators will employ task-oriented coping strategies, whereas passive procrastinators will be inclined to use either emotionoriented coping strategies or avoidance-oriented coping strategies. The ANOVA results in Table 2 supported this hypothesis. We identified significant differences among the three groups in task-oriented coping strategy $(F=6.21, p<.01)$ and avoidance-oriented coping strategy $(F=16.31, p<.001)$ but not in emotion-oriented coping strategy. Active procrastinators reported significantly greater use of the task-coping strategy than did passive procrastinators $(d=.55, p<.001)$, although the other two mean comparisons were not statistically significant. Both nonprocrastinators and active procrastinators reported significantly less use of avoidance-coping behavior than did passive procrastinators $(d \mathrm{~s}=.92$ and .68 , respectively, both $p \mathrm{~s}<.001)$. The results support Hypothesis 4 .

Personal outcomes. According to Hypothesis 5, nonprocrastinators and active procrastinators will experience less stress and depression and more life satisfaction and higher GPAs than will passive procrastinators. The present data largely confirmed this hypothesis. Among the three groups, significant differences were observed in stress $(F=14.94, p<.001)$, depression $(F=5.78, p<.01)$, and GPA $(F=9.79, p<.001)$. We found no significant differences between nonprocrastinators and active procrastinators on any of the four outcome measures, indicat- 
ing that these two groups achieved positive outcomes to a comparable degree (all $d \mathrm{~s}<.22, n s)$. In contrast, a series of paired $t$ tests showed that passive procrastinators were significantly different from both nonprocrastinators and active procrastinators, reporting greater stress, more feelings of depression, and lower GPAs (all $d \mathrm{~s}>.39, p \mathrm{~s}<.017$ ).

\section{Post Hoc Regression Analysis}

We could have directly tested the present hypotheses through a series of comparisons among the three different groups of individuals as shown in Table 2. However, because the present article describes the construct of active procrastination for the first time and because it is a continuous variable, it would be beneficial to understand how various attitude and coping variables that we use in the present study predict this new construct. To this end, we conducted regression analyses that evaluate the prediction of academic procrastination and active procrastination. As shown in Table 3, we used all variables that were included in this study as predictors, except the four outcome measures (stress, life satisfaction, depression, and GPA), because it is conceptually unlikely that these outcomes determine procrastination behavior.

The results showed that both (a) the traditional procrastination behavior as indicated by academic procrastination and (b) active procrastination behavior were negatively related to perceived time structure $(\beta=-.19, p<.01$, and $\beta=$ $-.13, p<.05$, respectively). However, only academic procrastination was associ-

TABLE 3. Regression Analyses Predicting Academic Procrastination and Active Procrastination

\begin{tabular}{lcc} 
Dependent variable & Academic procrastination & Active procrastination \\
\hline Time structure & $-.19^{* *}$ & $-.13^{*}$ \\
Purposive use of time & -.10 & .11 \\
Perceived time control & $-.35^{* * *}$ & .05 \\
Self-efficacy & .09 & $.18^{*}$ \\
Extrinsic motivation & -.04 & -.09 \\
Intrinsic motivation & .00 & .01 \\
Task coping & .05 & $.14^{*}$ \\
Emotion coping & .08 & -.01 \\
Avoidance coping & $.14^{*}$ & -.03 \\
Adjusted $R^{2}$ & .22 & .14 \\
$F(9,220)$ & $8.06^{* * *}$ & $5.10^{* * *}$ \\
\hline
\end{tabular}

Note. Entries are standardized regression coefficients $(\beta)$.

$* p<.05 . * * p<.01 . * * * p<.001$. 
ated with decreased perception of time control and increased avoidance-coping behavior $(\beta=-.35, p<.001$, and $\beta=.14, p<.05$, respectively). In contrast, active procrastination was positively related to self-efficacy and task-coping behavior $(\beta=.18, p<.05$, and $\beta=.14, p<.05$, respectively $)$.

\section{Discussion}

The purpose of the present study was to empirically test whether there are different types of procrastinators. In particular, we attempted to identify a positive type of procrastinator, which we termed active procrastinators. Contrary to prevailing assumptions about procrastinators, we revealed that a subset of procrastinators (i.e., active procrastinators) indeed possess desirable attitudinal and behavioral characteristics, even though they may engage in the same level of procrastination as "traditional" negative procrastinators (i.e., passive procrastinators). Members of this newly identified group of procrastinators, active procrastinators, prefer to work under pressure and make deliberate procrastination decisions. They are more likely to accomplish tasks with satisfactory outcomes than passive procrastinators, who are often paralyzed by indecision regarding action and haunted by past failure to complete tasks.

The present results indicate the possibility that nonprocrastinators and active procrastinators share similar characteristics and are significantly different from passive procrastinators. Nonprocrastinators and active procrastinators both tend to have higher levels of purposive use of time, time control, and self-efficacy than do passive procrastinators. In addition, nonprocrastinators and active procrastinators are more likely to experience positive outcomes. This pattern indicates that while active procrastinators procrastinate to the same degree as do passive procrastinators, mean difference $=-.10, t(151)=-.84$, their personal characteristics and outcomes are quite more similar to those of nonprocrastinators.

\section{Implications for Future Research}

We expected active procrastinators to structure their time to a high degree, as do nonprocrastinators. Unexpectedly, however, active procrastinators scored the lowest on the time structure scale, and there was no significant difference between nonprocrastinators and passive procrastinators. One possible explanation for this finding is that even though active procrastinators may plan their activities in an organized fashion, they do not restrict themselves to following a preplanned schedule or time structure. If something unexpectedly comes up, they will switch gears and engage in new tasks that they perceive as more urgent. In other words, active procrastinators may have more flexibly structured time and are more sensitive to changing demands in their environment. For this reason, they will act more spontaneously, resulting in more frequent temporal changes than with the other two groups. This interpretation, however, is only speculation. 
Future studies are needed to investigate the precise mechanisms underlying this unexpected pattern by examining variables such as degree of awareness of environmental demands or willingness to make changes.

In line with Conti's (2000) study, we hypothesized that both nonprocrastinators and active procrastinators will have a higher level of extrinsic motivation than will passive procrastinators. Interestingly, passive procrastinators turned out to have the highest level of extrinsic motivation. In the research setting of the present study, we constantly evaluated students' performance on the basis of externally imposed requirements, which often effectively reduce an individual's sense of autonomy and enjoyment in regard to a task (Deci \& Ryan, 1985). Therefore, students who have extrinsic reasons for studying may feel controlled and pressured and find the task to be aversive. To avoid these unpleasant feelings and perceptions of being forced to engage in particular activities, they might be more likely to postpone their academic work (Blunt \& Pychyl, 1998; Lay, 1990). Passive procrastinators, who have weak self-efficacy beliefs, may find imposed requirements unpleasant. For this reason, they may develop task aversion and postpone academic work to avoid feelings of incompetence. From this perspective, the only reason for passive procrastinators to perform tasks may be the threat of serious negative consequences for failing to perform.

\section{Potential Limitations}

Overall, the present study confirms the profile of nonprocrastinators and traditional procrastinators (i.e., passive procrastinators) in terms of their personal characteristics and outcomes (see Dipboye \& Phillips, 1990; Ferrari et al., 1992; Lay \& Schouwenburg, 1993; Tice \& Baumeister, 1997; Vodanovich \& Seib, 1997). This consistency with prior findings increases our confidence in the present results. Nevertheless, the current findings should be interpreted with caution because of several limitations of the present study. Our sample consisted of university students, who may possess different characteristics than other populations such as organizational employees. Therefore, the generalizability of the current results to populations engaging in other types of tasks is limited. Another limitation is that all variables were self-reported at one point in time. This cross-sectional nature of the data, which was obtained from a single source, raises the possibility of insensitivity to temporal changes of variables, ambiguous causal directions of the observed relationships, and boosted correlations among variables (Podsakoff \& Organ, 1986).

\section{Practical Implications}

Despite these limitations, the present study offers a new perspective on procrastination and how people perceive and use their time. In terms of practical implications, the current findings present a need to break our long-standing view 
of procrastination as an unhealthy or unproductive behavior. We should acknowledge the possibility that some forms of procrastination may actually enhance the well-being and performance of individuals. Active procrastination may be particularly beneficial, or even necessary, for individuals who work in highly demanding, unpredictable, and fast changing environments. In this type of context, active procrastinators may function more effectively than others by not restricting themselves to previously established plans and thus would be able to deal spontaneously with unexpected changes. They may constantly engage in a process of reprioritizing each of their tasks and thereby increase their capacity to more effectively meet frequently changing situational demands. Therefore, active procrastinators may function very effectively in highly uncertain situations with frequently changing environmental contingencies and demands. Future studies of this issue of person-situation fit may offer valuable contributions to managerial practice.

In the present study, we identified a positive form of procrastination. Future studies may expand the present findings with the use of different samples to replicate the presence of active procrastinators in other populations. Future investigators might also use a longitudinal research design to detect temporal changes in variables and to clarify the causal directions of the observed relationships. Moreover, conceptual efforts could be devoted to further clarification of the active procrastination construct. Once investigators have clearly defined the construct of active procrastination, and a valid measurement tool becomes available, the active procrastination construct could be compared with other potentially related personality constructs, such as those of Type A behavior or high-achievement orientation. It would also be meaningful to develop more precise descriptions of active procrastinators in terms of other personality traits such as the Big 5 factors or locus of control.

\section{REFERENCES}

Bandura, A. (1977). Self-efficacy: Toward a unifying theory of behavioral change. Psychological Review, 84, 191-215.

Bandura, A. (1986). Social foundations of thought and action: A social cognitive theory. Englewood Cliffs, NJ: Prentice-Hall.

Baumeister, R. F., Heatherton, T. F., \& Tice, D. M. (1994). Losing control: How and why people fail at self-regulation. San Diego: Academic Press.

Beswick, G., Rothblum, E., \& Mann, L. (1988). Psychological antecedents to student procrastination. Australian Psychologists, 23, 207-217.

Blunt, A., \& Pychyl, T. A. (1998). Volitional action and inaction in the lives of undergraduate students: State orientation, procrastination and proneness to boredom. Personality Individual Difference, 24, 837-846.

Bond, M. J., \& Feather, N. T. (1988). Some correlates of structure and purpose in the use of time. Journal of Personality and Social Psychology, 55, 321-329.

Brownlow, S., \& Reasinger, R. D. (2000). Putting off until tomorrow what is better done today: Academic procrastination as a function of motivation toward college work. Journal of Social Behavior and Personality, 15, 15-34.

Carver, C. S., Scheier, M. F., \& Weintraub, J. K. (1989). Assessing coping strategies: A 
theoretically based approach. Journal of Personality and Social Psychology, 56, 267-283.

Conti, R. (2000). Competing demands and complimentary motives: Procrastination on intrinsically and extrinsically motivated summer projects. Journal of Social Behavior and Personality, 15, 47-59.

Deci, E. L., \& Ryan, R. M. (1985). Intrinsic motivation and self-determination in human behavior. New York: Plenum Press.

Dipboye, R. L., \& Phillips, A. P. (1990). College students' time management: Correlations with academic performance and stress. Journal of Educational Psychology, 82, 760-768.

Ellis, A., \& Knaus, W. J. (1977). Overcoming procrastination. New York: Signet.

Endler, N. S., \& Parker, J. D. A. (1990). Multidimensional assessment of coping: A critical evaluation. Journal of Personality and Social Psychology, 58, 844-854.

Endler, N. S., \& Parker, J. D. A. (1994). Assessment of multidimensional coping: Task, emotion, and avoidance strategies. Psychological Assessment, 6, 50-60.

Fee, R. L., \& Tangney, J. P. (2000). Procrastination: A means of avoiding shame or guilt? Journal of Social Behavior and Personality, 15, 167-184.

Ferrari, J. R. (2001). Procrastination as self-regulation failure of performance: Effects of cognitive load, self-awareness, and time limits on "working best under pressure." European Journal of Personality, 15, 391-406.

Ferrari, J. R., Johnson, J. L., \& McCown, W. G. (1995). Procrastination and task avoidance: Theory, research, and treatment. New York: Plenum Press.

Ferrari, J. R., Parker, J. T., \& Ware, C. B. (1992). Academic procrastination: Personality correlates with Myers-Briggs types, self-efficacy, and academic locus of control. Journal of Social Behavior and Personality, 7, 595-602.

Ferrari, J. R., \& Tice, D. M. (2000). Procrastination as a self-handicap for men and women: A task-avoidance strategy in a laboratory setting. Journal of Research in Psychology, $34,73-83$.

Folkman, S., \& Lazarus, R. S. (1980). An analysis of coping in a middle-aged community sample. Journal of Health and Social Behavior, 21, 219-239.

Greenglass, E., Schwarzer, R., \& Taubert, S. (1999). The Proactive Coping Inventory (PCI): A multidimensional research instrument. Retrieved February 17, 2003, from http://userpage.fuberlin.de/ health/greenpci.htm

Harriott, J., \& Ferrari, J. (1996). Prevalence of procrastination among samples of adults. Psychological Reports, 78, 611-616.

Knaus, W. J. (2000). Procrastination, blame, and change. Journal of Social Behavior and Personality, 15, 153-166.

Kosic, A. (2004). Acculturation strategies, coping process and acculturative stress. Scandinavian Journal of Psychology, 45, 269-278.

Latack, J. C., \& Havlovic, S. J. (1992). Coping with job stress: A conceptual evaluation framework for coping measures. Journal of Organizational Behavior, 13, 479-508.

Lay, C. H. (1990). Working to schedule on personal projects: An assessment of personobject characteristics and trait procrastination. Journal of Social Behavior and Personality, 5, 91-104.

Lay, C. H., \& Schouwenburg, H. C. (1993). Trait procrastination, time management, and academic behavior. Journal of Social Behavior and Personality, 8, 647-662.

Macan, T. H. (1994). Time management: Test of a process model. Journal of Applied Psychology, 79, 381-391.

Macan, T. H., Shahani, C., Dipboye, R. L., \& Phillips, A. P. (1990). College students' time management: Correlations with academic performance and stress. Journal of Education Psychology, 82, 760-768. 
MacArthur, J. D., \& MacArthur, C. T. (2001). Perceived Stress Scale. Retrieved February 18, 2003, from Department of Psychology, University of California, San Francisco, Web site: http://www.macses.ucsf.edu/Research/Psychosocial/notebook/PSS10.html

Owens, A., \& Newbegin, I. (1997). Procrastination in high school achievement: A causal structural model. Journal of Social Behavior and Personality, 12, 869-887.

Podsakoff, P. M., \& Organ, D. W. (1986). Self-reports in organizational research: Problems and prospects. Journal of Management, 12, 531-544.

Rosenthal, R., \& Rosnow, R. L. (1991). Essentials of behavioral research: Methods and data analysis (2nd ed.). New York: McGraw-Hill.

Schwarzer, R., \& Jerusalem, M. (1995). Generalized Self-Efficacy Scale. In J. Weinman, S. Wright, \& M. Johnston, Measures in health psychology: A user's portfolio: Causal and control beliefs (pp. 35-37). Windsor, England: NFER-Nelson.

Sheikh, J. L., \& Yesavage, J. A. (1982). Geriatric Depression Scale (GDS). Retrieved February 18, 2003, from Department of Psychiatry and Behavioral Sciences, Stanford University, Web site: http://www.stanford.edu/ yesavage/GDS.english.long.html

Shia, R. M. (1998). Assessing academic intrinsic motivation: A look at student goals and personal strategy. Unpublished college thesis, Wheeling Jesuit University, Wheeling, WV. Retrieved February 17, 2003, from http://www.cet.edu/research/papers/motivation/motivation.pdf

Steel, P., Brothen, T., \& Wambach, C. (2001). Procrastination and personality performance, and mood. Personality and Individual Differences, 30, 95-106.

Tice, D., \& Baumeister, R. F. (1997). Longitudinal study of procrastination, performance, stress, and health: The cost and benefits of dawdling. Psychological Science, 8, 454-458.

Tuckman, B. W. (1991). The development and concurrent validity of the procrastination scale. Education and Psychological Measurement, 51, 473-480.

Vodanovich, S. J., \& Seib, H. M. (1997). Relationship between time structure and procrastination. Psychological Reports, 80, 211-215. 
Copyright of Journal of Social Psychology is the property of Heldref Publications and its content may not be copied or emailed to multiple sites or posted to a listserv without the copyright holder's express written permission. However, users may print, download, or email articles for individual use. 